\title{
Formation of hydroxyl radicals from photolysis of secondary organic aerosol material
}

\author{
K. M. Badali, S. Zhou, D. Aljawhary, M. Antiñolo, W. J. Chen, A. Lok, E. Mungall, J. P. S. Wong, R. Zhao, and \\ J. P. D. Abbatt \\ University of Toronto, 80 St. George Street, Toronto, Ontario, M5S 3H6, Canada \\ Correspondence to: S. Zhou (szhou@chem.utoronto.ca)
}

Received: 2 February 2015 - Published in Atmos. Chem. Phys. Discuss.: 17 February 2015

Revised: 3 June 2015 - Accepted: 3 June 2015 - Published: 16 July 2015

\begin{abstract}
This paper demonstrates that $\mathrm{OH}$ radicals are formed by photolysis of secondary organic aerosol (SOA) material formed by terpene ozonolysis. The SOA is collected on filters, dissolved in water containing a radical trap (benzoic acid), and then exposed to ultraviolet light in a photochemical reactor. The $\mathrm{OH}$ formation rates, which are similar for both $\alpha$-pinene and limonene SOA, are measured from the formation rate of p-hydroxybenzoic acid as measured using offline HPLC analysis. To evaluate whether the $\mathrm{OH}$ is formed by photolysis of $\mathrm{H}_{2} \mathrm{O}_{2}$ or organic hydroperoxides ( $\mathrm{ROOH}$ ), the peroxide content of the SOA was measured using the horseradish peroxidase-dichlorofluorescein (HRP-DCF) assay, which was calibrated using $\mathrm{H}_{2} \mathrm{O}_{2}$. The $\mathrm{OH}$ formation rates from SOA are 5 times faster than from the photolysis of $\mathrm{H}_{2} \mathrm{O}_{2}$ solutions whose concentrations correspond to the peroxide content of the SOA solutions, assuming that the HRPDCF signal arises from $\mathrm{H}_{2} \mathrm{O}_{2}$ alone. The higher rates of $\mathrm{OH}$ formation from SOA are likely due to $\mathrm{ROOH}$ photolysis, but we cannot rule out a contribution from secondary processes as well. This result is substantiated by photolysis experiments conducted with t-butyl hydroperoxide and cumene hydroperoxide which produce over 3 times more $\mathrm{OH}$ than photolysis of equivalent concentrations of $\mathrm{H}_{2} \mathrm{O}_{2}$. Relative to the peroxide level in the SOA and assuming that the peroxides drive most of the ultraviolet absorption, the quantum yield for $\mathrm{OH}$ generation from $\alpha$-pinene SOA is $0.8 \pm 0.4$. This is the first demonstration of an efficient photolytic source of $\mathrm{OH}$ in SOA, one that may affect both cloud water and aerosol chemistry.
\end{abstract}

\section{Introduction}

Given the importance of secondary organic aerosol (SOA) to both climate and air quality, considerable attention has been given to studying the formation pathways and composition of SOA both in the lab and the field (Hallquist et al., 2009). However, less attention has been paid to its reactive properties and how the chemical nature of the particles may change as they transit through the atmosphere (Jimenez et al., 2009). If the particles become more hygroscopic, then they will be wet scavenged more easily. Similarly, their resultant health effects may transform if reactive functional groups are either produced or lost during processing.

One direction has been to address the multi-phase oxidation processes in which SOA participates, primarily via oxidation by gas-phase $\mathrm{OH}$ radicals (George and Abbatt, 2010). The conclusions from these studies are that heterogeneous exposure to $\mathrm{OH}$ leads to a more oxidized and hygroscopic aerosol, with small amounts of mass loss through fragmentation reactions occurring on a timescale of a few days of equivalent $\mathrm{OH}$ exposure in the atmosphere.

A second, less explored direction for SOA processing studies has been with respect to photochemical aging in the presence of ultraviolet light. In initial studies, many by Nizkorodov and co-workers, it has been shown that oxidative aging can also occur, leading to the formation of small molecules in the gas phase (e.g. $\mathrm{HCHO}, \mathrm{HCOOH}, \mathrm{CO}$ ), rapid loss of condensed phase carbonyls, and some degree of mass loss (Walser et al., 2007; Mang et al., 2008; Bateman et al., 2011; Henry and Donahue, 2012; Epstein et al., 2014; Wong et al., 2014). The rates of this chemistry are dependent on environmental conditions, such as relative humidity (Wong et al., 2014). It is not clear from these experiments whether 
the aging occurs through only primary photochemical reactions or whether secondary processes also occur, initiated by radical production in a primary photochemical step. These photochemical aging experiments may be especially important for the change in optical properties of organic aerosol, especially for photobleaching of brown carbon species that absorb in the visible and near UV range (Sareen et al., 2013; Lee et al., 2014; Zhong and Jang, 2014; Zhao et al., 2015).

To further our understanding of this photochemical aging mechanism, it is necessary to evaluate the potential for oxidant production within tropospheric particles. Although it is known that gas-phase $\mathrm{OH}$ radicals collide with particles giving rise to oxidation, probably at the surface of the particle, the intrinsic sources of $\mathrm{OH}$ within a particle have not been well quantified. There are a number of routes that $\mathrm{OH}$ could form (Herrmann et al., 2010). The presence of soluble iron, for example, could lead to $\mathrm{OH}$ production through the Fenton reaction. Photochemical processes have been suggested as well, primarily through analogy to chemistry occurring in cloud water, such as the production of $\mathrm{OH}$ through the photolysis of efficient photochemical sources such as dissolved nitrate, nitrite, and hydrogen peroxide.

In this paper we measure the formation rate of $\mathrm{OH}$ radicals that occurs when SOA constituents are photolyzed, most likely through the photodissociation of organic hydroperoxide $(\mathrm{ROOH})$. The presence of $\mathrm{ROOH}$ in SOA, especially ozonolysis SOA formed from terpenes, is likely (Ehn et al., 2014). They may form via Criegee biradicals, generated when ozone reacts with a carbon-carbon double bond, and also through $\mathrm{H}$-abstractions that are part of chain oxidation mechanisms (Crounse et al., 2013; Ehn et al., 2014). Indeed, it is likely that the molecular structures of extremely low volatility organic compounds (ELVOCs) formed in the ozonolysis of $\alpha$-pinene consist of numerous hydroperoxide functional groups mounted on the background of ringopened functionalized $\alpha$-pinene starting material. Secondary chemistry may also occur in aerosol subsequent to initial photolytic formation of radicals, producing additional photoactive $\mathrm{ROOH}$ species.

A number of past studies have quantitatively investigated the association of different peroxide species with SOA ( $\mathrm{Li}$ et al., 2002; Docherty et al., 2005; Chen and Hopke, 2009a, b, 2010; Wang et al., 2011; Bateman et al., 2011; Mertes et al., 2012; Mutzel et al., 2013). In a study conducted by Li et al. (2002), the concentrations of $\mathrm{H}_{2} \mathrm{O}_{2}$ and $\mathrm{ROOH}$ formed during the ozonolysis of limonene were measured in both the gas and particle phases simultaneously. It was estimated that roughly $1 \mathrm{ppb}$ of peroxide was generated from the reaction at limonene and ozone levels relevant to indoor conditions. A study by Docherty et al. (2015) measured the yields of total organic peroxides in SOA formed through the ozonolysis of $\alpha$ - and $\beta$-pinene, $\Delta$-3carene, and sabinene, reporting high yields of $47-85 \%$ of the SOA mass. Chen and Hopke measured peroxides associated with particles formed using $\alpha$-pinene, limonene, and linalool VOC precursors and mea- sured their stability under different conditions (Chen and Hopke, 2009a, b, 2010); this was followed by the work of Wang et al. (2011) who also investigated peroxide formation and stability associated with SOA formed through the oxidation of $\alpha$ - and $\beta$-pinene and toluene precursors. Mertes et al. (2012) generated $\alpha$-pinene SOA, measuring peroxide yields of $12-34 \%$ of the SOA mass. A study by Bateman et al. (2011) measured the yields of peroxides from limonene SOA, reporting a value of $2 \%$ in terms of the moles of SOA collected. The stability of the peroxides under photolytic conditions was also evaluated, finding that there was no significant change in peroxide levels following $14 \mathrm{~h}$ of photolysis, probably because of the formation of smaller peroxides during photo-processing.

The importance of a photochemical $\mathrm{OH}$ source in SOA is that the $\mathrm{OH}$ radical may lead to oxidation processes within aerosol particles and cloud water. In aerosol particles in particular, with small aqueous volumes, the partitioning properties of volatile species such as $\mathrm{H}_{2} \mathrm{O}_{2}$ indicate that little is expected to reside in the particles. Additionally, it is possible that other $\mathrm{OH}$ sources, such as nitrate ions, are not fully mixed with the SOA, especially when the particle has phase separated into inorganic-rich and organic-rich components. However, $\mathrm{OH}$ generated from SOA will be well mixed on a molecular scale with other SOA materials and so able to drive oxidative processes. A recent laboratory study has illustrated how $\mathrm{OH}$ generation within particles can lead to rapid oxidation of organic constituents (Daumit et al., 2014).

We describe experiments in which we photolyze SOA material generated in an environmental chamber after it is collected and then dissolved in water. We use an aqueous radical trap, benzoic acid (Klein et al., 1975; Anastasio and McGregor, 2001), to measure the $\mathrm{OH}$ production rate. To relate $\mathrm{OH}$ generation rates to the composition of the SOA, we apply a standard assay (horseradish peroxidase-dichlorofluorescein, HRP-DCF) to measure the peroxide content of the aerosol components (Keston and Brandt, 1965). Assuming that the peroxide signal arising from the HRP-DCF assay is due to the presence of $\mathrm{H}_{2} \mathrm{O}_{2}$, we compare the $\mathrm{OH}$ production rates from dissolved SOA to the rate from solutions with corresponding concentrations of $\mathrm{H}_{2} \mathrm{O}_{2}$. We find that the $\mathrm{OH}$ production rates from SOA are substantially higher than from the pure $\mathrm{H}_{2} \mathrm{O}_{2}$ solutions, implying that species other than hydrogen peroxide - likely organic hydroperoxide - are photolyzing into $\mathrm{OH}$. To our knowledge, this is the first quantitative evaluation of the potential for SOA material to photolyze to form $\mathrm{OH}$. As part of the study, we also perform detailed stability tests of the peroxides within SOA, as measured with the HRP-DCF assay, both in solution and on filter to better establish their environmental relevance. 
(a)

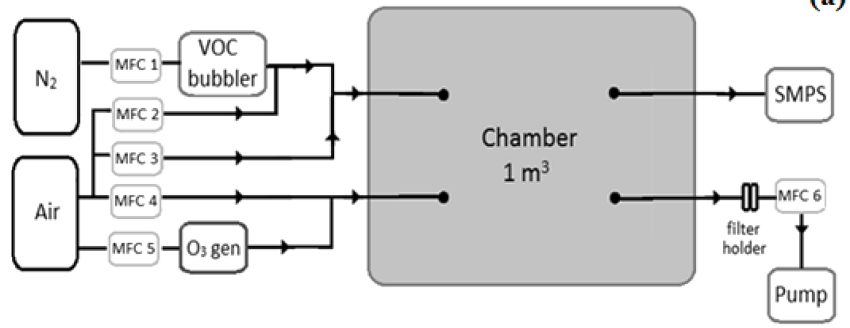

(b)

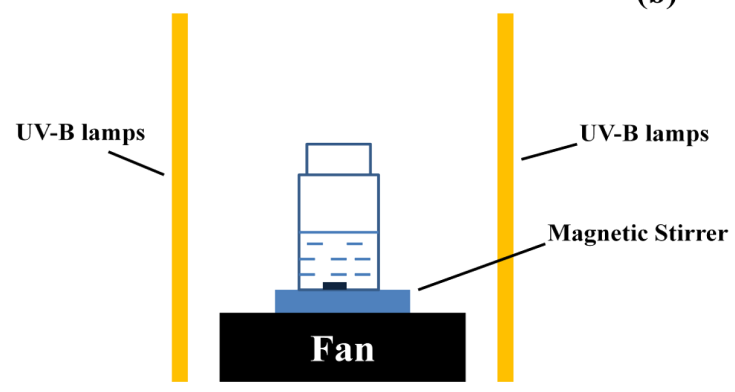

Figure 1. Schematic diagrams of the environmental chamber (a) and the photoreactor (b).

\section{Methods}

\subsection{SOA collection using an environmental chamber}

An environmental chamber was used to collect SOA samples both to evaluate peroxide yields and for the photolysis experiments (see Fig. 1a). The chamber is a $1 \mathrm{~m}^{3}$ Teflon bag supported by a Teflon-coated frame. The bag is externally surrounded by metal panels, preventing exposure to outside light. The chamber was operated in continuous mode with all flows controlled by mass flow controllers. Ozone was generated by flowing purified air over a $185 \mathrm{~nm}$ mercury pen-ray lamp, with a flow rate of 6 standard $\mathrm{L} \min ^{-1}$ (MFC 5, see Fig. 1a). A dilution flow of air of 7 standard $\mathrm{L} \mathrm{min}^{-1}$ (MFC 4) is mixed with the ozone flow prior to being introduced into the chamber. Limonene was introduced to the chamber using a $10 \mathrm{sccm}$ flow of nitrogen through a headspace bubbler chilled at $5{ }^{\circ} \mathrm{C}$ (MFC 1). $\alpha$-Pinene was introduced to the chamber through a $12 \mathrm{sccm}$ flow from a custom cylinder with a certified mixing ratio (320 ppm $\pm 20 \% \alpha$-pinene in nitrogen, Air Liquide). The VOC flows were carried with a dilution flow of air of $500 \mathrm{sccm}$ (MFC 2), meeting an additional dilution flow of 2.2 standard $\mathrm{L} \mathrm{min}^{-1}$ (MFC 3 ) before entering the chamber through a stainless steel port. The total flow rate through the chamber was held at 15 standard $\mathrm{L} \mathrm{min}^{-1}$ using a diaphragm pump (MFC 6). Aerosol samples were collected on supported PTFE filters (Zefluor, Pall Life Sciences, $47 \mathrm{~mm}$ diameter, $2.0 \mu \mathrm{M}$ pore size) for $2 \mathrm{~h}$, collecting an average of 185 and $900 \mu \mathrm{g}$ of $\alpha$-pinene and limonene SOA respectively.
The ozone levels within the chamber were periodically measured using an ozone analyzer (Thermo Environmental Instruments Inc, Model 49C). Approximately $320 \mathrm{ppb}$ of ozone was introduced to the chamber, while excesses of 85 and $140 \mathrm{ppb}$ of ozone were measured at the exit of the chamber during $\alpha$-pinene and limonene experiments respectively. The mixing ratio of limonene in the chamber was measured prior to oxidation to be $250 \mathrm{ppbv}$ by a proton-transfer reaction mass spectrometer (Ionicon Analytik $\mathrm{GmbH}$ ); that of $\alpha$-pinene was also $250 \mathrm{ppbv}$ as determined from flow rates from the certified cylinder. The mass loadings of SOA within the chamber while collection was proceeding were roughly $100 \mu \mathrm{g} \mathrm{m}^{-3}$ for $\alpha$-pinene experiments, and $500 \mu \mathrm{g} \mathrm{m}^{-3}$ for limonene experiments, as inferred from the mass of aerosol collected on the filter, the flow rate, and the collection time.

\subsection{SOA storage and extraction}

Following collection, SOA samples were either extracted immediately or else stored for stability studies. To extract, filter samples were placed in a foil-covered Teflon bottle with $15 \mathrm{~mL}$ deionized water $(18 \mathrm{~m} \Omega$, Millipore) and placed on a shake table for $15 \mathrm{~min}$ at $420 \mathrm{rpm}$. Following extraction, an aliquot of each sample was immediately prepared for analysis using the HRP-DCF assay or used for photochemistry experiments.

To evaluate in-solution stability, extracted solutions were covered with parafilm and foil and stored in the dark at room temperature. Those for on-filter stability testing were weighed and immediately placed in a sealed plastic filter holder (Analyslide petri dish, Pall Life Sciences). For the stability studies, samples were placed either in a dark cupboard at room temperature or in a sealed plastic bag and stored in a dark freezer at $-20^{\circ} \mathrm{C}$. Frozen samples were brought to room temperature before being removed from the filter holder to prevent the condensation of contaminants onto the filter surface.

\subsection{Horseradish peroxidase-dichlorofluorescein assay}

A stock solution of $2^{\prime}, 7^{\prime}$-dichlorofluorescein diacetate $(1 \mathrm{mM}$ DCFHDA, $\mathrm{C}_{24} \mathrm{H}_{14} \mathrm{C}_{12} \mathrm{O}_{7}$, Sigma-Aldrich) was prepared in methanol and stored at $-20^{\circ} \mathrm{C}$. The DCFHDA was converted to the hydrolyzed $2^{\prime}, 7^{\prime}$-dichlorofluorescein (DCFH) form by adding $1.0 \mathrm{~mL}$ DCFHDA to $4.0 \mathrm{~mL}$ sodium hydroxide $(0.01 \mathrm{M}, \mathrm{NaOH})$ and allowing the hydrolysis to proceed for $30 \mathrm{~min}$ at room temperature. The fluorescing solution, referred to as HRP-DCF, was prepared by mixing $4.0 \mathrm{~mL}$ of DCFH with $7.0 \mathrm{mg}$ of peroxidase from horseradish (HRP, Type I, Sigma-Aldrich), brought to a final volume of $100 \mathrm{~mL}$ with pH 7.2 phosphate buffer $\left(7.35 \mathrm{mM} \mathrm{KH}_{2} \mathrm{PO}_{4}, 17.6 \mathrm{mM}\right.$ $\mathrm{Na}_{2} \mathrm{HPO}_{4}$ ). The HRP-DCF solution was kept in amber bottles on ice until needed.

Hydrogen peroxide standards were freshly prepared for the calibration of each assay. A stock solution $\left(1 \mathrm{mM} \mathrm{H}_{2} \mathrm{O}_{2}\right.$, 
made with $\mathrm{H}_{2} \mathrm{O}_{2} 30 \%$ wt ACS reagent, Sigma Aldrich) was prepared in deionized water, used for standard dilutions ranging from 2 to $20 \mu \mathrm{M} \mathrm{H}_{2} \mathrm{O}_{2}$. Calibration standards were stored in amber bottles on ice until needed. The limit of detection of the HRP-DCF assay is $0.1 \mu \mathrm{M} \mathrm{H}_{2} \mathrm{O}_{2}$.

Calibration curves were also prepared using commercial sources of t-butyl hydroperoxide (Luperox TBH70X, 70 wt $\%$ in $\mathrm{H}_{2} \mathrm{O}$, Sigma Aldrich), cumene hydroperoxide (technical grade, $80 \%$, Sigma Aldrich), and di-t-butyl peroxide (Luperox DI, $98 \%$, Sigma Aldrich). The signal responses were respectively 97,94 , and $96 \%$ lower than for hydrogen peroxide. Commercially available organic peroxides are those that are relatively stable. Thus, we conclude that the HRP-DCF response will be either due to dissolved $\mathrm{H}_{2} \mathrm{O}_{2}$ or to peroxides more unstable than those commercially available.

Assay samples were prepared by adding $250 \mu \mathrm{L}$ of the sample to $2.25 \mathrm{~mL}$ HRP-DCF in Teflon-capped amber vials. Samples were briefly mixed before reacting at room temperature in the dark for $30 \mathrm{~min}$. The reaction was quenched by putting vials on ice for $30 \mathrm{~s}$ before measuring the sample fluorescence. A spectrometer/fluorometer (SpectroVis Plus, Vernier) was operated in fluorescence mode with a $500 \mathrm{~nm}$ excitation light source, measuring sample spectra at $523.9 \mathrm{~nm}$. Data were collected using Logger Pro software (version 3.8.2, Vernier).

\subsection{Measurement of $\mathrm{OH}$ production rates}

Photolysis of $50 \mathrm{~mL}$ volumes of SOA solutions was conducted in a photochemical reactor in which a $100 \mathrm{~mL}$ glass vessel was situated in the centre of an array of UV-B fluorescent lamps (see Fig. 1b). The spectrum of the lamps was measured with a spectral radiometer (StellaNet Inc.) and the magnitude of the flux (see Fig. 2) was calibrated by measuring the photoisomerization rate of 2-nitrobenzaldehyde (for details, see Zhao et al., 2015).

SOA solutions were prepared by mixing equal volumes of aqueous solutions of SOA and benzoic acid (BA), a known $\mathrm{OH}$ radical trap, resulting in final SOA and BA concentrations of $250 \mu \mathrm{M}$ and $1.0 \mathrm{mM}$ respectively where the SOA material is assumed to have an average effective molecular weight of $200 \mathrm{~g} \mathrm{~mole}^{-1}$ (Bateman et al., 2011). The solutions were photolyzed for $1 \mathrm{~h}$ with $2.5 \mathrm{~mL}$ samples taken at 30 and 60 min for subsequent analysis. $\mathrm{OH}$ production rates are measured by the formation of para-hydroxybenzoic acid (PHBA), measured using HPLC, where all sample solutions were acidified immediately prior to injection with 2 drops of $1.0 \mathrm{mM} \mathrm{H}_{2} \mathrm{SO}_{4}$. A glass injection syringe was rinsed five times with deionized water and five times with sample solution. Sample solutions were analyzed using a $150 \mathrm{~mm} \mathrm{C-18}$ column with fixed wavelength detector at $\lambda=256 \mathrm{~nm}$ and detector range $=0.01$. A 15 min, four-step gradient elution method was employed using mobile phase composed of acetonitrile and trifluoroacetic acid in deionized water.

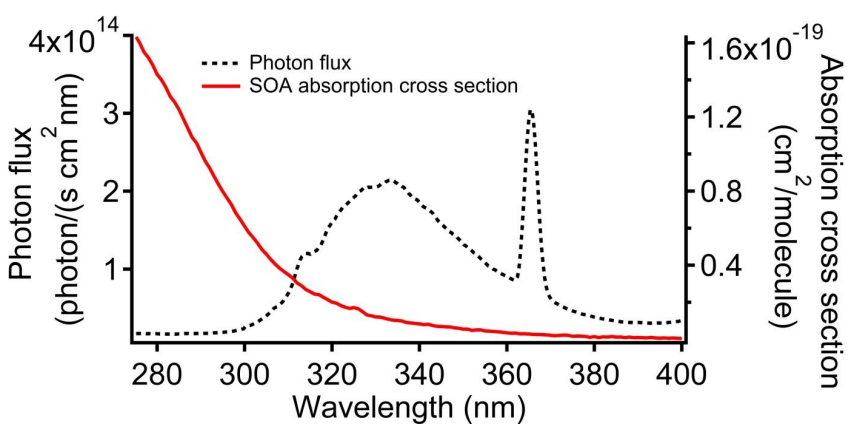

Figure 2. Photon flux (dashed line) inside the glass vessel in the photoreactor and SOA absorption cross section from Wong et al. (2014) (solid line).

PHBA forms in solution from $\mathrm{OH}$ reacting with benzoic acid with a yield of $20 \%$ (Klein et al., 1975; Anastasio and McGregor, 2001). Based on experiments conducted with $0.25,0.50$, and $1.0 \mathrm{mM}$ benzoic acid, it was determined that $1.0 \mathrm{mM}$ solutions trap all the $\mathrm{OH}$ generated. In particular, more OH was trapped in SOA photolysis experiments conducted with $0.50 \mathrm{mM}$ BA solutions than with $0.25 \mathrm{mM}$ solutions, but the amount trapped in 0.50 and $1.0 \mathrm{mM}$ runs was the same within experimental error. Overall, the detection limit for $\mathrm{OH}$ production rate within the SOA solutions was on the order of $1 \times 10^{-10} \mathrm{M} \mathrm{s}^{-1}$, as determined largely by background amounts of PHBA present in the solutions without illumination.

Photolysis experiments were also performed with $12.5 \mu \mathrm{M}$ solutions of commercial organic hydroperoxides, namely tbutyl hydroperoxide and cumene hydroperoxide, and hydrogen peroxide.

\section{Results and discussion}

\subsection{SOA peroxide yields and thermal stability}

A series of experiments was conducted with the HRP-DCF assay both to determine how best to handle SOA samples to preserve their peroxide content and also to gain some information on the nature of the peroxides present in the SOA, especially when dissolved in water. In particular, HRPDCF peroxide yields (see Table 1) from fresh SOA samples were measured immediately following collection and the 15 min aqueous extraction period. The yields have been reported in three ways: (1) mole percentage, moles of peroxides/moles of SOA $\times 100 \%$, where the molecular weight of SOA is assumed to be $200 \mathrm{~g} \mathrm{~mole}^{-1}$ (Bateman et al., 2011); (2) mass percentage, mass of peroxides/mass of SOA collected $\times 100 \%$, where the molecular weight of peroxides is assumed to be $34 \mathrm{~g} \mathrm{~mole}^{-1}$; and (3) normalized yield, moles of peroxides/mass of SOA collected, where the peroxides are assumed to be $\mathrm{H}_{2} \mathrm{O}_{2}$. 
Table 1. Peroxide yields from fresh SOA samples (this study) and from literature reports (see text for explanation).

\begin{tabular}{|c|c|c|c|c|}
\hline$\alpha$-Pinene & Detection method & Yield ( $\%$ mole) & Yield (\% mass) & Normalized $\left(\right.$ mole $\left.\mu \mathrm{g}^{-1}\right)$ \\
\hline This study - chamber & HRP-DCF & $3.1 \pm 0.5$ & $0.5 \pm 0.1$ & $(1.6 \pm 0.3) \times 10^{-10}$ \\
\hline Docherty et al. (2005) & Iodide & - & $47 \pm 12$ & - \\
\hline Chen and Hopke (2009a) & HRP-DCF & - & - & $\left(1.8 \pm 0.8 \times 10^{-10}\right.$ \\
\hline Wang et al. (2011) & HRP-PHOPAA* & - & - & $(2.7 \pm 1.1) \times 10^{-11}$ \\
\hline Mertes et al. (2012) & Iodide & - & $34 \pm 4$ & - \\
\hline Limonene & Detection method & Yield (\% mole) & Yield (\% mass) & Normalized (mole $\mu \mathrm{g}^{-1}$ ) \\
\hline This study - chamber & HRP-DCF & $5.1 \pm 0.1$ & $0.45 \pm 0.01$ & $(1.42 \pm 0.03) \times 10^{-10}$ \\
\hline Chen and Hopke (2010) & HRP-DCF & - & - & $(1.6 \pm 0.1) \times 10^{-10}$ \\
\hline Bateman et al. (2011) & Iodide & 2 & - & $\sim 1 \times 10^{-10}$ \\
\hline
\end{tabular}

* PHOPAA is para-hydroxyphenylacetic acid

Peroxide yields were also measured using SOA generated in a flow tube (see Supplement, Fig. S1) with mass loadings at least 10 times higher than those generated in the chamber. These results demonstrate that mass loading does not have a large effect on peroxide yields in SOA, at least over the range of conditions explored. For example, the fresh yields from chamber SOA were $3.1 \pm 0.5 \%$ mole for $\alpha$-pinene and $5.1 \pm 0.1 \%$ mole for limonene, very similar to those from SOA collected using the flow tube: $4.2 \pm 0.6 \%$ mole and $3.8 \pm 0.7 \%$ mole respectively. Uncertainties quoted reflect variability from between three and seven replicates, whereas we estimate absolute uncertainties are on the order of $\pm 20 \%$.

The HRP-DCF peroxide yields from $\alpha$-pinene and limonene SOA only comprise a few percent of the total moles of SOA material. These values are comparable to the results reported by Chen and Hopke, who also used the HRP-DCF assay to measure peroxides from SOA formed through $\alpha$ pinene and limonene ozonolysis (Chen and Hopke, 2009a, 2010). The studies by both Docherty et al. (2005) and Mertes et al. (2012) used the iodide technique to quantify their peroxide species. This technique is sensitive to organic peroxides (i.e. ROOH and ROOR) and therefore the yields reported by these studies are considered to be the total peroxide content of the SOA. The study by Bateman et al. (2011) also used the iodide method to quantify peroxides, using $\mathrm{H}_{2} \mathrm{O}_{2}$ to calibrate the fluorescence response. The other studies using the iodide method calibrated the assay using benzoyl peroxide, an organic peroxide that may have a different sensitivity to the assay than hydrogen peroxide. Finally, the study by Wang et al. (2011) reported yields that were somewhat lower than the $\alpha$-pinene yields in this study. This study also used HRP as their catalyst; however, they used an HPLC technique to speciate the peroxides, and para-hydroxyphenylacetic acid was used in the place of dichlorofluorescein.

As noted in the Methods section, the sensitivity of the HRP-DCF assay heavily favours $\mathrm{H}_{2} \mathrm{O}_{2}$ although a weak sensitivity to commercial organic hydroperoxides exists. A control experiment was conducted in which a very high gas- phase concentration of $\mathrm{H}_{2} \mathrm{O}_{2}$ (created by bubbling $250 \mathrm{sccm}$ $\mathrm{N}_{2}$ through $30 \% \mathrm{H}_{2} \mathrm{O}_{2}$ solution) was passed through a Teflon filter for $1 \mathrm{~h}$. Upon extraction in water and HRP-DCF analysis, it was found that no measurable amount of $\mathrm{H}_{2} \mathrm{O}_{2}$ had adhered to the filter. This indicates that the peroxides measured in this work were not in the form of $\mathrm{H}_{2} \mathrm{O}_{2}$ when present in the aerosol particles, as expected from the high volatility of $\mathrm{H}_{2} \mathrm{O}_{2}$. Rather, the signal is most likely due to $\mathrm{ROOH}$ in the particle. These molecules may have a direct response in the HRP-DCF assay, higher than the stable commercial organic hydroperoxides. Also, it is possible that some of the signal arises from $\mathrm{H}_{2} \mathrm{O}_{2}$ when SOA material is put into solution. For example, a general class of compounds, the $\alpha$ hydroxyhydroperoxides, exist in equilibrium in water with hydrogen peroxide and organics containing carbonyl functional groups, especially aldehydes (Zhao et al., 2013). These species can be formed through the hydrolysis reaction of Criegee intermediates. Similar conclusions have been made previously (Wang et al., 2011).

Support for the formation of some $\mathrm{H}_{2} \mathrm{O}_{2}$ in solution comes from a set of stability experiments conducted both in solution and on the filter, using SOA generated in the flow tube. As shown in the Supplement (see Fig. S2), the stability in aqueous solutions of $\alpha$-pinene and limonene SOA had very similar trends following extraction. Within the first $48 \mathrm{~h}$ after extraction, the amount of peroxide in solution increased by approximately $50 \%$ of its original yield. After $48 \mathrm{~h}$, the peroxide slowly decayed. A control experiment was performed in which the Teflon filter was removed from the aqueous solution following the initial 15 min extraction period. In this sample, the same increase in peroxide yields was observed within the first $48 \mathrm{~h}$ following extraction. If the peroxides in the particle begin as organic hydroperoxides, the increase in yield may be due to a gradual decomposition reaction to form $\mathrm{H}_{2} \mathrm{O}_{2}$ within the first $48 \mathrm{~h}$. Although the total peroxide content in the extract may not be changing, a larger fraction would be present in the $\mathrm{H}_{2} \mathrm{O}_{2}$ form. Since the HRP-DCF assay is very sensitive to $\mathrm{H}_{2} \mathrm{O}_{2}$, this could account for the in- 


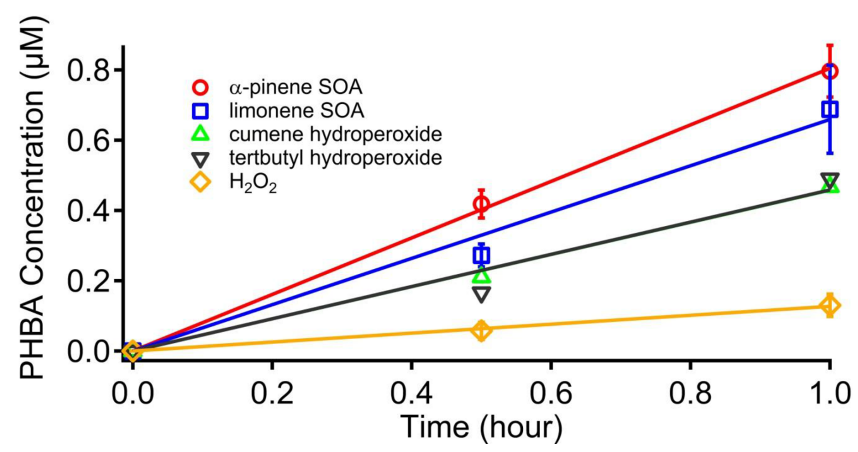

Figure 3. Concentrations of p-hydroxybenzoic acid (PHBA) formed by photolysis experiments for $250 \mu \mathrm{M}$ solutions of SOA and $12.5 \mu \mathrm{M}$ solutions of commercial hydroperoxides. Fits are lines of best fit, forced through the origin.

crease in yields. We note that the increase in signal in aqueous solutions is similar to that reported by Wang et al. (2011) where an increase in $\mathrm{H}_{2} \mathrm{O}_{2}$ content was observed within the initial $20 \mathrm{~h}$ following extraction, followed by a period of stability until approximately $80 \mathrm{~h}$ after extraction.

A suite of experiments was also conducted to examine the thermal stability of the peroxide yields, as shown in Fig. S2 as a function of filter age before extraction. At room temperature, a loss of peroxide was observed with increasing filter age for both $\alpha$-pinene and limonene SOA. Unlike the stability at room temperature, the peroxide yields were stable when the filters were stored in the freezer at $-20^{\circ} \mathrm{C}$ for up to 7 days. The loss observed at room temperature is likely due to volatilization of small species, or perhaps the decomposition of species such as the $\alpha$-hydroxyhydroperoxides present on the filter into $\mathrm{H}_{2} \mathrm{O}_{2}$ (as discussed above), followed by volatilization. At low temperature, the volatilization and reaction rates of the organic peroxides are expected to be much slower than at room temperature, thus stabilizing the signal. This is in accord with previous work (Chen and Hopke, 2010; Wang et al., 2011).

\subsection{OH generation rates from photolysis}

The rates of PHBA formation from the $250 \mu \mathrm{M} \alpha$-pinene and limonene SOA solutions are shown in Fig. 3. For each set of data, a small background signal of PHBA measured with no light exposure at zero time has been subtracted from the data. The backgrounds are no larger than $20 \%$ of the signal at full time exposure. As well, four sets of control experiments were conducted for $1 \mathrm{~h}$ each - SOA mixed with benzoic acid in the dark, SOA on its own with light, SOA on its own in the dark, and benzoic acid on its own in light - to confirm that the PHBA signal measured arises from SOA photolysis to form $\mathrm{OH}$. In each control experiment, the change of signal over $1 \mathrm{~h}$ was negligible: no more than $10 \%$ of the PHBA signal with SOA, benzoic acid, and light present simultaneously. Addi- tional control experiments were conducted to confirm that BA and PHBA were photolytically stable for our conditions.

It is seen in Fig. 3 that PHBA forms in a linear manner with time when SOA is photolyzed for $1 \mathrm{~h}$ in the presence of benzoic acid, arising from the formation of $\mathrm{OH}$ in solution. Both types of SOA form $\mathrm{OH}$ with roughly the same efficiency. In the same figure are also included the results for photolysis experiments conducted with $12.5 \mu \mathrm{M}$ solutions of the two commercial organic hydroperoxides and $\mathrm{H}_{2} \mathrm{O}_{2}$. Note that the concentrations of the latter solutions are $5 \%$ of the concentration of the SOA solution, i.e. roughly matching the measured peroxide yields from the SOA with the HRP-DCF assay (see Table 1). Interestingly, the $\mathrm{OH}$ yields from the hydrogen peroxide solutions are a factor of 5 times smaller than those from SOA, whereas those from the organic hydroperoxides are more comparable, within a factor of 2 . This indicates that the signal from the HRP-DCF assay for the SOA solutions does not arise solely from $\mathrm{H}_{2} \mathrm{O}_{2}$ photolysis. Instead, there must be other species in solution, likely $\mathrm{ROOH}$ molecules, that form $\mathrm{OH}$ upon UV illumination.

\section{Conclusions and environmental implications}

\subsection{SOA peroxides}

Although total peroxide yields have been reported previously there is considerable uncertainty in their interpretation as described above, dependent in part on the methods of analysis (see Table 1). The assays that have been used are non-specific, with the iodide approach sensitive to both ROOH and ROOR species and the HRP-DCF method sensitive to $\mathrm{H}_{2} \mathrm{O}_{2}$ and probably some $\mathrm{ROOH}$ species. As described above, the peroxide stability studies indicate that the HRP-DCF peroxide signal is stable when filters are stored frozen, likely because there is no decomposition and subsequent loss of volatile species that are HRP-DCF active. Also, the solution studies show that a more active species, likely $\mathrm{H}_{2} \mathrm{O}_{2}$, is slowly formed in solution within the first $24 \mathrm{~h}$ perhaps from the decomposition of soluble species such as $\alpha$-hydroxyhydroperoxides. These molecules are known to decompose to form hydrogen peroxide and organics with carbonyl functional groups (Wang et al., 2011; Zhao et al., 2013). We note in general that methods for the accurate speciation and quantification of complex $\mathrm{ROOH}$ species are poorly developed, and limit some of the conclusions that can be made in this work and in the field in general.

The peroxides present in the particles have potential to influence photochemical pathways, as will be discussed below, but also to affect human health. SOA can be either inhaled directly or can deposit on indoor surfaces where it can become part of the semi-volatile organic matter that is known to be ubiquitously present (Liu et al., 2003). For the airborne particles, peroxides associated with the SOA, as one component of the general class of molecules referred to as reactive 
Table 2. $\mathrm{OH}$ radical production rates from photolysis of $250 \mu \mathrm{M}$ solutions of SOA and $12.5 \mu \mathrm{M}$ solutions of commercial peroxides, as calculated from the data in Fig. 3 using literature values for the yield of PHBA from the $\mathrm{OH}$ oxidation of benzoic acid (see text for details).

\begin{tabular}{lc}
\hline Sample & $\begin{array}{c}\text { OH production rate } \\
\left(\times 10^{-10} \mathrm{M} \mathrm{s}^{-1}\right)\end{array}$ \\
\hline$\alpha$-Pinene SOA & $11.0 \pm 0.5$ \\
Limonene SOA & $9.0 \pm 1.5$ \\
Hydrogen peroxide & $2.0 \pm 0.5$ \\
t-Butyl hydroperoxide & $6.5 \pm 1.5$ \\
Cumene hydroperoxide & $6.5 \pm 0.5$ \\
\hline
\end{tabular}

oxygen species (ROS), have the potential to cause oxidative stress upon inhalation. Based on our work, it is expected that the peroxides exist as organic hydroperoxides in the particles - and not as $\mathrm{H}_{2} \mathrm{O}_{2}$ - thus allowing them to be carried deep into the respiratory system. Being volatile and soluble, it is unlikely that gas-phase $\mathrm{H}_{2} \mathrm{O}_{2}$ can pass long distances into the respiratory pathways. Once the particles deposit and dissolve in the lung fluid, the organic hydroperoxides may decompose to form $\mathrm{H}_{2} \mathrm{O}_{2}$, a potent ROS constituent.

\subsection{Photochemical generation of $\mathrm{OH}$}

The primary result from this work is that photolysis of SOA material generates $\mathrm{OH}$ in solution, likely from $\mathrm{ROOH}$ species. In particular, the quantum yield for gas-phase t-butyl hydroperoxide is unity (Baasandorj et al., 2010). Also, the effective quantum yield for $\mathrm{OH}$ formation from $\mathrm{H}_{2} \mathrm{O}_{2}$ in solution is also close to unity (Herrmann et al., 2010; Goldstein et al., 2007).

For this work, to calculate the overall quantum yield of $\mathrm{OH}$ from $\alpha$-pinene SOA peroxides we first calculate the firstorder rate constant $\left(k_{\mathrm{OH}}\right)$ describing $\mathrm{OH}$ formation:

$[\mathrm{OH}]_{\mathrm{t}}=[\text { Peroxide }]_{\mathrm{o}}\left(1-\exp \left(-k_{\mathrm{OH}} t\right)\right)$,

where $[\mathrm{OH}]_{\mathrm{t}}$ refers to the time-dependent concentration of $\mathrm{OH}$ and $[\text { Peroxide }]_{\mathrm{o}}$ represents the maximum concentration of $\mathrm{OH}$ that will form from peroxide photolysis at infinite time, assuming that one $\mathrm{OH}$ radical can form from one peroxide molecule. To make this calculation, we convert the PHBA formation rates in Fig. 3 (i.e. the slopes of the lines of best fit) into $\mathrm{OH}$ formation rates assuming a yield of $20 \%$ of PHBA from reaction of $\mathrm{OH}$ with benzoic acid (Klein et al., 1975; Anastasio and McGregor, 2001). The results are given in Table 2. Using Eq. (1), the rate constant for $\mathrm{OH}$ production from $\alpha$-pinene SOA photolysis is thus calculated to be $(1.4 \pm 0.4) \times 10^{-4} \mathrm{~s}^{-1}$, where the uncertainty arises from estimated absolute uncertainties in the measured $\mathrm{OH}$ production rate and the peroxide concentration of the $\alpha$-pinene SOA solution.
We then express this photolysis rate constant, $k_{\mathrm{OH}}$, in terms of the wavelength $(\lambda)$-dependent light intensity in the reactor $(I(\lambda))$, the SOA absorption cross section $(\sigma(\lambda))$, and the quantum yield $(\varphi(\lambda))$ :

$k_{\mathrm{OH}}=\int I(\lambda) \sigma(\lambda) \varphi(\lambda) \mathrm{d}(\lambda)$,

where we have previously published the molecular absorption cross section for $\alpha$-pinene SOA generated in the same environmental chamber (Wong et al., 2014). Note that by doing so we are referencing the quantum yield to the total concentration of peroxides in solution (i.e. assuming that the $\mathrm{OH}$ is arising from the peroxides) and we are assuming that the absorption cross section measured for SOA is determined by these peroxides in the pertinent wavelength range. While the absorption in the long-wavelength tail is likely due to other species, peroxides are likely to contribute to some degree to the short wavelength absorption. We do not know the degree to which other functional groups, such as carbonyls, also contribute.

By integrating this expression and equating it to the experimental $k_{\mathrm{OH}}$ value (i.e. $(1.4 \pm 0.4) \times 10^{-4} \mathrm{~s}^{-1}$ ), we calculate the peroxide quantum yield for aqueous $\alpha$-pinene SOA to be $0.8 \pm 0.4$. This value represents an average effective quantum yield, assumed to be wavelength independent, for all routes to $\mathrm{OH}$ formation in solution. Its large value close to unity provides support that SOA peroxides are indeed the source of the $\mathrm{OH}$ measured. Using the same approach and literature values for the absorption cross section (FinlaysonPitts and Pitts, 2000), we calculate the quantum yield for $\mathrm{OH}$ production from $\mathrm{H}_{2} \mathrm{O}_{2}$ in our experiments to be $1.1 \pm 0.4$, in agreement within experimental uncertainties with values in the literature (Goldstein et al., 2007; Herrmann et al., 2010).

We cannot determine from these data alone whether the $\mathrm{OH}$ is formed only in a primary step, as from the photolysis of a $\mathrm{ROOH}$ functional group that is part of the original SOA material, or whether secondary chemistry also contributes. For example, subsequent chemistry might involve the following:

$$
\begin{aligned}
& \mathrm{ROOH}+h v \rightarrow \mathrm{RO}+\mathrm{OH} \\
& \mathrm{RO} \rightarrow \mathrm{R}^{\prime}+\mathrm{R}^{\prime \prime} \mathrm{HCO} \\
& \mathrm{R}^{\prime}+\mathrm{O}_{2} \rightarrow \mathrm{R}^{\prime} \mathrm{O}_{2} \\
& \mathrm{R}^{\prime} \mathrm{O}_{2}+\mathrm{HO}_{2} \rightarrow \mathrm{R}^{\prime} \mathrm{OOH}+\mathrm{O}_{2} \\
& \mathrm{R}^{\prime} \mathrm{OOH}+h v \rightarrow \mathrm{R}^{\prime} \mathrm{O}+\mathrm{OH} .
\end{aligned}
$$

The $\mathrm{HO}_{2}$ that is needed in Reaction (R4) can be formed by photolysis of aldehydes that are part of the SOA material or from those generated in Reaction (R2),

$$
\begin{aligned}
& \mathrm{R}^{\prime \prime} \mathrm{HCO}+h v \rightarrow \mathrm{R}^{\prime \prime}+\mathrm{HCO} \\
& \mathrm{HCO}+\mathrm{O}_{2} \rightarrow \mathrm{HO}_{2}+\mathrm{CO},
\end{aligned}
$$

and potentially from the oxidation of benzoic acid. The $\mathrm{HO}_{2}$ can then go on to form $\mathrm{H}_{2} \mathrm{O}_{2}$ (Hullar and Anastasio, 2011),

$\mathrm{HO}_{2}+\mathrm{HO}_{2} \rightarrow \mathrm{H}_{2} \mathrm{O}_{2}+\mathrm{O}_{2}$, 
which may generate $\mathrm{OH}$ upon photolysis.

An indication that secondary chemistry may be occurring is that we would have expected the primary $\mathrm{OH}$ production rate to start to level off at $1 \mathrm{~h}$ reaction time due to the consumption of hydroperoxide species for the measured initial rate constant of $1.4 \times 10^{-4} \mathrm{~s}^{-1}$, if primary photolysis is the only production route of $\mathrm{OH}$. The fact that the production rate remains linear with time may indicate a secondary source of $\mathrm{OH}$. Catalytic formation of ELVOC-like compounds during the $\mathrm{OH}$ oxidation may represent a sustained source of hydroperoxides in addition to the mechanisms outlined above.

There are different approaches to assess the potential impact that SOA materials may have on condensed phase $\mathrm{OH}$ production rates in the atmosphere. To start, it is important to distinguish between cloud water and aerosol environments. For the very high liquid water volumes present in cloud water, highly soluble species that are also $\mathrm{OH}$ sources are present in reasonably high amounts. For example, $\mathrm{H}_{2} \mathrm{O}_{2}$ is present through Henry's Law solubility at the 10 to $100 \mu \mathrm{M}$ level for ambient gas-phase mixing ratios of 0.1 to $1 \mathrm{ppbv}$ (Sakugawa et al., 1990). The corresponding concentration of SOA materials is not straightforward to estimate. Cloud water dissolved organic carbon (DOC) amounts range from a few $\mathrm{mgC} \mathrm{L}^{-1}$ up to many tens of $\mathrm{mgC} \mathrm{L}^{-1}$ in polluted environments (Herckes et al., 2013). Taking $10 \mathrm{mgC} \mathrm{L}^{-1}$ as a representative value, an $\mathrm{OM} / \mathrm{OC}$ ratio of 2 , and assuming a molecular weight of $100 \mathrm{~g} \mathrm{~mole}^{-1}$ for dissolved species (i.e. a combination of low molecular soluble species and higher molecular weight humic-acid-like molecules), this corresponds to a concentration of DOC species on the order of $200 \mu \mathrm{M}$. Only 10 to $50 \%$ of DOC species has been identified at the molecular level as small soluble molecules (Herckes et al., 2013), making it possible that dissolved organics from SOA and other sources constitute the remaining fraction, i.e. roughly on the order of $100 \mu \mathrm{M}$. Thus, the SOA concentrations in cloud water may be comparable to those of $\mathrm{H}_{2} \mathrm{O}_{2}$ or even higher. In terms of $\mathrm{OH}$-generating efficiency, Table 2 illustrates that SOA, on a per molar basis, is about 5 times less efficient than $\mathrm{H}_{2} \mathrm{O}_{2}$. However, the lower efficiency of $\mathrm{OH}$ production from SOA as compared to $\mathrm{H}_{2} \mathrm{O}_{2}$ may be offset by higher dissolved concentrations, making the SOA an important $\mathrm{OH}$ source in cloud water. Confirmation of this hypothesis requires better speciation of organic materials in cloud water that arise from SOA.

Following this line of thought forward to aerosol particles, the concentrations of dissolved species such as $\mathrm{H}_{2} \mathrm{O}_{2}$ will not be significantly higher than in cloud water. However, the concentrations of SOA materials will be very much larger, approaching molar values, which will make the SOA much more important as a photolytic $\mathrm{OH}$ source.

From another perspective, we can compare our $\mathrm{OH}$ photolytic formation rates to the formation rates of $\mathrm{OH}$ in cloud and aerosol that have been calculated based on known concentrations of constituents and known photochemistry and taking into account mass transfer from the gas phase (Arakaki et al., 2013). Formation rates vary widely from values of $10^{-10} \mathrm{M} \mathrm{s}^{-1}$ in rainwater to $10^{-9} \mathrm{M} \mathrm{s}^{-1}$ in cloud and fog to $10^{-7}$ to $10^{-6} \mathrm{M} \mathrm{s}^{-1}$ in marine aerosol particles. By comparison, we observed $\mathrm{OH}$ production rates of $10^{-9} \mathrm{M} \mathrm{s}^{-1}$ for our $250 \mu \mathrm{M}$ SOA solutions. Given that $250 \mu \mathrm{M}$ is not an inappropriate DOC concentration for cloud water conditions, especially if highly polluted (Herckes et al., 2013), this shows that the source has the potential to compete with more conventional $\mathrm{OH}$ sources, such as $\mathrm{H}_{2} \mathrm{O}_{2}$. The formation rate would be very much higher under aerosol water conditions given the high concentrations of SOA in such particles. We note that mass transfer of $\mathrm{OH}$ from the gas phase is also important for the overall $\mathrm{OH}$ flux and can compete with these condensed-phase formation pathways.

\section{The Supplement related to this article is available online at doi:10.5194/acp-15-7831-2015-supplement.}

Acknowledgements. The authors would like to acknowledge NSERC and the Sloan Foundation for providing support for this project. M. Antiñolo thanks the Fundación Ramón Areces for funding.

Edited by: V. F. McNeill

\section{References}

Anastasio, C. and McGregor, K. G.: Chemistry of fog waters in California's Central Valley: 1. In situ photoformation of hydroxyl radical and singlet molecular oxygen, Atmos. Environ., 35, 1079-1089, doi:10.1016/s1352-2310(00)00281-8, 2001.

Arakaki, T., Anastasio, C., Kuroki, Y., Nakajima, H., Okada, K., Kotani, Y., Handa, D., Azechi, S., Kimura, T., Tsuhako, A., and Miyagi, Y.: A General Scavenging Rate Constant for Reaction of Hydroxyl Radical with Organic Carbon in Atmospheric Waters, Environ. Sci. Technol., 47, 8196-8203, doi:10.1021/es401927b, 2013.

Baasandorj, M., Papanastasiou, D. K., Talukdar, R. K., Hasson, A. S., and Burkholder, J. B.: $\left.\left(\mathrm{CH}_{3}\right){ }_{3}\right) \mathrm{COOH}$ (tert-butyl hydroperoxide): $\mathrm{OH}$ reaction rate coefficients between 206 and $375 \mathrm{~K}$ and the $\mathrm{OH}$ photolysis quantum yield at $248 \mathrm{~nm}$, Phys. Chem. Chem. Phys., 12, 12101-12111, doi:10.1039/c0cp00463d, 2010.

Bateman, A. P., Nizkorodov, S. A., Laskin, J., and Laskin, A.: Photolytic processing of secondary organic aerosols dissolved in cloud droplets, Phys. Chem. Chem. Phys., 13, 12199-12212, doi:10.1039/c1cp20526a, 2011.

Chen, X. and Hopke, P. K.: Secondary organic aerosol from alphapinene ozonolysis in dynamic chamber system, Indoor Air, 19, 335-345, doi:10.1111/j.1600-0668.2009.00596.x, 2009a.

Chen, X. and Hopke, P. K.: A chamber study of secondary organic aerosol formation by linalool ozonolysis, Atmos. Environ., 43, 3935-3940, doi:10.1016/j.atmosenv.2009.04.033, 2009b. 
Chen, X. and Hopke, P. K.: A chamber study of secondary organic aerosol formation by limonene ozonolysis, Indoor Air, 20, 320328, 10.1111/j.1600-0668.2010.00656.x, 2010.

Crounse, J. D., Nielsen, L. B., Jorgensen, S., Kjaergaard, H. G., and Wennberg, P. O.: Autoxidation of Organic Compounds in the Atmosphere, J. Phys. Chem. Lett., 4, 3513-3520, doi:10.1021/jz4019207, 2013.

Daumit, K. E., Carrasquillo, A. J., Hunter, J. F., and Kroll, J. H.: Laboratory studies of the aqueous-phase oxidation of polyols: submicron particles vs. bulk aqueous solution, Atmos. Chem. Phys., 14, 10773-10784, doi:10.5194/acp-14-10773-2014, 2014.

Docherty, K. S., Wu, W., Lim, Y. B., and Ziemann, P. J.: Contributions of organic peroxides to secondary aerosol formed from reactions of monoterpenes with $\mathrm{O}_{3}$, Environ. Sci. Technol., 39, 4049-4059, doi:10.1021/es050228s, 2005.

Ehn, M., Thornton, J. A., Kleist, E., Sipila, M., Junninen, H., Pullinen, I., Springer, M., Rubach, F., Tillmann, R., Lee, B., LopezHilfiker, F., Andres, S., Acir, I. H., Rissanen, M., Jokinen, T., Schobesberger, S., Kangasluoma, J., Kontkanen, J., Nieminen, T., Kurten, T., Nielsen, L. B., Jorgensen, S., Kjaergaard, H. G., Canagaratna, M., Dal Maso, M., Berndt, T., Petaja, T., Wahner, A., Kerminen, V. M., Kulmala, M., Worsnop, D. R., Wildt, J., and Mentel, T. F.: A large source of low-volatility secondary organic aerosol, Nature, 506, 476-479, doi:10.1038/nature13032, 2014.

Epstein, S. A., Blair, S. L., and Nizkorodov, S. A.: Direct Photolysis of a-Pinene Ozonolysis Secondary Organic Aerosol: Effect on Particle Mass and Peroxide Content, Environ. Sci. Technol., 48, 11251-11258, doi:10.1021/es502350u, 2014.

Finlayson-Pitts, B. J. and Pitts, J. N.: Chemistry of the upper and lower troposphere: Theory, experiments and applications, Academic Press, San Diego, 2000.

George, I. J. and Abbatt, J. P. D.: Heterogeneous oxidation of atmospheric aerosol particles by gas-phase radicals, Nature Chemistry, 2, 713-722, doi:10.1038/nchem.806, 2010.

Goldstein, S., Aschengrau, D., Diamant, Y., and Rabani, J.: Photolysis of aqueous $\mathrm{H}_{2} \mathrm{O}_{2}$ : Quantum yield and applications for polychromatic UV actinometry in photoreactors, Environ. Sci. Technol., 41, 7486-7490, doi:10.1021/es071379t, 2007.

Hallquist, M., Wenger, J. C., Baltensperger, U., Rudich, Y., Simpson, D., Claeys, M., Dommen, J., Donahue, N. M., George, C., Goldstein, A. H., Hamilton, J. F., Herrmann, H., Hoffmann, T., Iinuma, Y., Jang, M., Jenkin, M. E., Jimenez, J. L., Kiendler-Scharr, A., Maenhaut, W., McFiggans, G., Mentel, Th. F., Monod, A., Prévôt, A. S. H., Seinfeld, J. H., Surratt, J. D., Szmigielski, R., and Wildt, J.: The formation, properties and impact of secondary organic aerosol: current and emerging issues, Atmos. Chem. Phys., 9, 5155-5236, doi:10.5194/acp-9-51552009, 2009.

Henry, K. M. and Donahue, N. M.: Photochemical Aging of $\alpha$-Pinene Secondary Organic Aerosol: Effects of $\mathrm{OH}$ Radical Sources and Photolysis, J. Phys. Chem. A, 116, 5932-5940, doi:10.1021/jp210288s, 2012.

Herckes, P., Valsaraj, K. T., and Collett, J. L.: A review of observations of organic matter in fogs and clouds: Origin, processing and fate, Atmos. Res., 132, 434-449, doi:10.1016/j.atmosres.2013.06.005, 2013.

Herrmann, H., Hoffmann, D., Schaefer, T., Brauer, P., and Tilgner, A.: Tropospheric Aqueous-Phase Free-Radical Chemistry: Radical Sources, Spectra, Reaction Kinetics and Prediction Tools,
Chemphyschem., 11, 3796-3822, doi:10.1002/cphc.201000533, 2010.

Hullar, T. and Anastasio, C.: Yields of hydrogen peroxide from the reaction of hydroxyl radical with organic compounds in solution and ice, Atmos. Chem. Phys., 11, 7209-7222, doi:10.5194/acp11-7209-2011, 2011.

Jimenez, J. L., Canagaratna, M. R., Donahue, N. M., Prevot, A. S. H., Zhang, Q., Kroll, J. H., DeCarlo, P. F., Allan, J. D., Coe, H., Ng, N. L., Aiken, A. C., Docherty, K. S., Ulbrich, I. M., Grieshop, A. P., Robinson, A. L., Duplissy, J., Smith, J. D., Wilson, K. R., Lanz, V. A., Hueglin, C., Sun, Y. L., Tian, J., Laaksonen, A., Raatikainen, T., Rautiainen, J., Vaattovaara, P., Ehn, M., Kulmala, M., Tomlinson, J. M., Collins, D. R., Cubison, M. J., Dunlea, E. J., Huffman, J. A., Onasch, T. B., Alfarra, M. R., Williams, P. I., Bower, K., Kondo, Y., Schneider, J., Drewnick, F., Borrmann, S., Weimer, S., Demerjian, K., Salcedo, D., Cottrell, L., Griffin, R., Takami, A., Miyoshi, T., Hatakeyama, S., Shimono, A., Sun, J. Y., Zhang, Y. M., Dzepina, K., Kimmel, J. R., Sueper, D., Jayne, J. T., Herndon, S. C., Trimborn, A. M., Williams, L. R., Wood, E. C., Middlebrook, A. M., Kolb, C. E., Baltensperger, U., and Worsnop, D. R.: Evolution of Organic Aerosols in the Atmosphere, Science, 326, 1525-1529, doi:10.1126/science.1180353, 2009.

Keston, A. S., and Brandt, R.: Fluorometric analysis of ultramicro quanitities of hydrogen peroxide, Anal. Biochem., 11, 1-5, doi:10.1016/0003-2697(65)90034-5, 1965.

Klein, G. W., Bhatia, K., Madhavan, V., and Schuler, R. H.: Reaction of $\mathrm{OH}$ with benzoic-acid-isomer distribution in radical intermediates, J. Phys. Chem., 79, 1767-1774, doi:10.1021/j100584a005, 1975.

Lee, H. J., Aiona, P. K., Laskin, A., Laskin, J., and Nizkorodov, S. A.: Effect of Solar Radiation on the Optical Properties and Molecular Composition of Laboratory Proxies of Atmospheric Brown Carbon, Environ. Sci. Technol., 48, 1021710226, doi:10.1021/es502515r, 2014.

Li, T. H., Turpin, B. J., Shields, H. C., and Weschler, C. J.: Indoor hydrogen peroxide derived from ozone/d-limonene reactions, Environ. Sci. Technol., 36, 3295-3302, doi:10.1021/es015842s, 2002.

Liu, Q. T., Chen, R., McCarry, B. E., Diamond, M. L., and Bahavar, B.: Characterization of polar organic compounds in the organic film on indoor and outdoor glass windows, Environ. Sci. Technol., 37, 2340-2349, doi:10.1021/es020848i, 2003.

Mang, S. A., Henricksen, D. K., Bateman, A. P., Andersen, M. P. S., Blake, D. R., and Nizkorodov, S. A.: Contribution of carbonyl photochemistry to aging of atmospheric secondary organic aerosol, J. Phys. Chem. A, 112, 8337-8344, doi:10.1021/jp804376c, 2008.

Mertes, P., Pfaffenberger, L., Dommen, J., Kalberer, M., and Baltensperger, U.: Development of a sensitive long path absorption photometer to quantify peroxides in aerosol particles (PeroxideLOPAP), Atmos. Meas. Tech., 5, 2339-2348, doi:10.5194/amt5-2339-2012, 2012.

Mutzel, A., Rodigast, M., Iinuma, Y., Boege, O., and Herrmann, H.: An improved method for the quantification of SOA bound peroxides, Atmos. Environ., 67, 365-369, doi:10.1016/j.atmosenv.2012.11.012, 2013. 
Sakugawa, H., Kaplan, I. R., Tsai, W., and Cohen, Y.: Atmospheric hydrogen peroxide, Environ. Sci. Technol., 24, 14521462, doi:10.1021/es00080a002, 1990.

Sareen, N., Moussa, S. G., and McNeill, V. F.: Photochemical Aging of Light-Absorbing Secondary Organic Aerosol Material, J. Phys. Chem. A, 117, 2987-2996, doi:10.1021/jp309413j, 2013.

Walser, M. L., Park, J., Gomez, A. L., Russell, A. R., and Nizkorodov, S. A.: Photochemical aging of secondary organic aerosol particles generated from the oxidation of d-limonene, J. Phys. Chem. A, 111, 1907-1913, doi:10.1021/jp0662931, 2007.

Wang, Y., Kim, H., and Paulson, S. E.: Hydrogen peroxide generation from alpha- and beta-pinene and toluene secondary organic aerosols, Atmos. Environ., 45, 3149-3156, doi:10.1016/j.atmosenv.2011.02.060, 2011.

Wong, J. P. S., Zhou, S., and Abbatt, J. P. D.: Changes in secondary organic aerosol composition and mass due to photolysis: relative humidity dependence, J. Phys. Chem. A., 2015, 4309-4316, doi:10.1021/jp506898c, 2014.
Zhao, R., Lee, A. K. Y., Soong, R., Simpson, A. J., and Abbatt, J. P. D.: Formation of aqueous-phase a-hydroxyhydroperoxides $(\alpha$ HHP): potential atmospheric impacts, Atmos. Chem. Phys., 13, 5857-5872, doi:10.5194/acp-13-5857-2013, 2013.

Zhao, R., Lee, A. K. Y., Huang, L., Li, X., Yang, F., and Abbatt, J. P. D.: Photochemical processing of aqueous atmospheric brown carbon, Atmos. Chem. Phys., 15, 6087-6100, doi:10.5194/acp15-6087-2015, 2015.

Zhong, M. and Jang, M.: Dynamic light absorption of biomassburning organic carbon photochemically aged under natural sunlight, Atmos. Chem. Phys., 14, 1517-1525, doi:10.5194/acp-141517-2014, 2014. 